\title{
E-Learning and Open Distance Education (ODL) in IPRC Kigali during COVID-19 Pandemic Spread: Opportunities and Challenges Available
}

\author{
Noel Mporananayo $^{1 *} \quad$ Schadrack Niyonzima $^{2} \quad$ Claude Mukeshimana $^{2}$ \\ Laurent AHISHAKIYE ${ }^{2}$ James MBONYUBURYO ${ }^{2}$ \\ 1.Tutorial Assistant at Rwanda Polytechnic/Integrated Polytechnic Regional College - Kigali, Rwanda \\ 2.Assistant Lecturer at Rwanda Polytechnic/Integrated Polytechnic Regional College - Kigali, Rwanda
}

\begin{abstract}
This study entitled "E-Learning and Open Distance education (ODL) in IPRC Kigali during COVID-19 Pandemic spread: Opportunities and Challenges available" was conducted to examine the opportunities available for IPRC Kigali students who were learning via Rwanda Polytechnic E-Learning platform, established to maintain the learning process and contain COVID-19 pandemic spread. It also examined the challenges they encountered during this period. More than $60 \%$ of the student-respondents supported the statement saying that their E-learning platform is able to provide opportunities for relations between learners by the use of the discussion forum. The respondents agreed that E-learning offers opportunities for learning for a maximum number of trainees with no need for many building. Therefore more than $67 \%$ of them found this as an opportunity. More than $63 \%$ also agreed that a small number of teaching staff may deliver courses to a big number of students at the same time. The majority of them did not accept that the students' mindsets prevent them from accessing the E-learning platform (48.1\%). They didn't also agree on the statement that lecturers/instructors have a little experience in delivering courses through Distance Learning mode (65.4\%). This shows that they are proud of their teaching staff. It was recommended that to address the issue of impossibility to control malpractice; the use of appropriate software used in other universities would be adopted; the government should speed up the distribution of laptops to students who have not received them yet; there should be sensitization to change the students' mindsets and join E-Learning platform; trainers should design appropriate online learning resources and provide timely feedback to students, and emerging technologies like zoom, Microsoft teams, WebEx, Google meet ... videoconferencing, social media, and other virtual classrooms should be considered.
\end{abstract}

Keywords: E-Learning, ODL, opportunities, challenges, ICT

DOI: $10.7176 / \mathrm{JEP} / 11-27-04$

Publication date:September $30^{\text {th }} 2020$

\section{Introduction}

1.1 Background to the study

Online teaching and learning is emerging as a growing trend in Open and Distance Learning (ODL) and gaining wider popularity among Higher Education institutions in Africa. Online teaching and learning in the context of this study, refers to a method of instruction and acquisition of knowledge that is carried out in ODL with the help of computer and technologies via internet (Ivy \& Jane, 2016). E-Learning has become a worldwide phenomenon in the new technological economy, crossing oceans and reaching to remote villages. The entry visa for e-learning is a computer and an Internet connection [1]. Integration of ICT competency into a nursing curriculum is important to ensure success throughout the education and career of contemporary ... students (Harerimana, et al., 2016). Many research studies have been conducted on e-learning and Open Distance Learning and some of the following are the findings:

The concept of distance education evolving through generations provides a helpful structure when considering history and heritage. The majority of distance education today takes place using the Internet, now readily accessible for the vast majority of students whether in their own homes or at facilities such as local libraries. These electronic means are used to distribute the learning material, keep students in touch with teachers, and provide access to communication between students (Liudmila \& Nataliya, 2020). In 1989 Nipper, the first to use a generational framework, suggested three generations of distance education linked to production, distribution, and computer conferencing. Subsequently, these three generations were often labelled correspondence, broadcast, and computer mediated (Bill \& Mary, 2012).

The above researchers continued their statements saying: "The first two generations are fairly universally accepted. However, different writers, building on Nipper's work, have constructed subsequent generations somewhat differently." They spelt out that the first generation of distance education was defined by print technology where a combination of printing press technology and postal services made what is commonly known as correspondence education that was widely available. The second generation was based on the use of radios and televisions in Distance Education. There was an improvement since those broadcast technologies enhanced and 
added value to Distance Education.

Computer-mediated education has also caught the attention of face-to-face teaching institutions. It presents such institutions with possibilities for engaging with current students who seek greater flexibility in the delivery of courses, and with new cohorts of distance students (Bill \& Mary ,2012). Not only the flexibility to students matters but also the learning environment and the response to the challenges the world is facing have imposed the use of IT tools to allow teaching and learning continue. The current situation of COVID-19 pandemic spread has forced all the institutions to work from home. Students shouldn't be left behind. Even though they were not much conversant with e-learning platforms, they had to be online learning.

In an expository study conducted on Distance Learning Program of Teachers at Kigali Institute of Education; the researcher stated that Kigali Institute of Education was established in January 1999 by the Government of Rwanda to help address the shortage of qualified teaching staff at the secondary level and the shortage of managerial staff needed to run technical and vocational training institutions. She continues stating that Although Kigali Institute of Education started by offering an on-campus program, in order to fulfill its mission of providing Rwanda with qualified teachers, the Institute determined it needed to establish a distance learning (DL) program as a compliment to its existing on-campus learning and teaching model. Distance learning became an alternative for two reasons. First, because there are many under qualified in-service teachers working on the ground, and second, there are no qualified teachers to replace them should they leave for training and upgrading. Distance education, therefore, was chosen as a viable mode of training delivery for this targeted group of educators (MUKAMUSONI, September 2006).

In her findings, she found that most of the staff had little experience in delivering through Distance Learning mode before joining the program. This was due to an unusually wide variety of skills that are required for both on the part of academic and non-academic staff, the competencies required to organize and run a DL program that were not typically available. Although capacity building and staff development are important to all aspects of the Institute's DL program, it becomes even more important in course materials development because, in most cases, DL course materials are developed by lecturers from on-campus programs (MUKAMUSONI, September 2006).

Another study was conducted to find out the practices and challenges of Distance Training Program under Kigali Institute of Education and many challenges have been identified. Amongst them, there was: lack of adequate infrastructure, students drop out, lack of working and teaching-learning materials, irregularities in students attendance, lack of assistants who would assist in students support, content which was difficult to understand, and limited interaction between trainers-trainees and trainees-trainees (NDAYAMBAJE, BIMENYIMANA, \& NDAHAYO, 2015)

On the other hand, in a study conducted to analyze the interplay between policy formulation and interpretation in terms of historical practices of ODL in Rwanda has come out with the findings revealing that though policies extolled ODL potential to increase access, relevance and inclusion in education, and though they highlight the need to improve quality in higher education through affordable, scalable and sustainable technologies, implementing institutions tend to adopt contentious approaches to cope with a dual mode (Mukama, 2018).

The above research studies findings have been conducted before COVID-19 pandemic spread. This has forced institutions to establish the E-learning platforms. Both students and teaching staff were not equipped with relevant skills needed for teaching learning processes. This has introduced some opportunities and challenges.

\subsection{Statement of the problem}

Since December 2019, COVID-19 pandemic spread in China and later on started spreading all over the world. Different countries started taking measures to contain the pandemic spread including school closure. On 14th March 2020, Rwanda was put into total lockdown. All the schools in Rwanda were closed since then. The government requested schools, IPRC Kigali inclusive, to establish E-Learning platforms. These platforms are currently operational. IPRCs are available on Rwanda Polytechnic platform which is https://elearning.rp.ac.rw. Since then, IPRC Kigali staff and students registered to join their classes. Some students have not joined and up to now they can't join. This study aimed at investigating the opportunities gained by students who managed to join the platform, the challenges encountered by them and those who did not sign in.

1.3 The purpose of the study

The purpose of this study was to investigate the available e-learning opportunities and challenges to students during COVID-19 pandemic in IPRC Kigali.

14 Objective of the study

To assess the perception of IPRC Kigali students on the current e-learning opportunities and available the challenges.

1.4 Research hypothesis

Some IPRC Kigali students have benefited from the established e-learning platform, others have encountered 
challenges.

1.5 Significance of the study

This study will provide solutions to challenges encountered by students and these may improve further requirements to establish e-learning platforms even in difficult learning situations.

\section{Literature review}

\subsection{Historical Background of Open and Distance Learning}

E-learning refers to the use of information and communication technologies to enable the access to online learning/teaching resources (Valentina \& Nelly, 2014). It is divided into two basic types: computer-based elearning and internet based e-learning.

The concept of distance education evolving through generations provides a helpful structure when considering history and heritage. The majority of distance education today takes place using the Internet, now readily accessible for the vast majority of students whether in their own homes or at facilities such as local libraries. These electronic means are used to distribute the learning material, keep students in touch with teachers, and provide access to communication between students (Liudmila \& Nataliya, 2020). In 1989 Nipper, the first to use a generational framework, suggested three generations of distance education linked to production, distribution, and computer conferencing. Subsequently, these three generations were often labeled correspondence, broadcast, and computer mediated (Bill \& Mary, 2012).

The above researchers continued their statements saying: "The first two generations are fairly universally accepted. However, different writers, building on Nipper's work, have constructed subsequent generations somewhat differently." They spelt out that the first generation of distance education was defined by print technology where a combination of printing press technology and postal services made what is commonly known as correspondence education that was widely available. The second generation was based on the use of radios and televisions in Distance Education. There was an improvement since those broadcast technologies enhanced and added value to Distance Education.

There were other subsequent generations like the use of asynchronous computer conferencing (teleconferencing (audio and video) to enrich delivery. Both audio and video conferencing extended interaction and highlighted the need to develop facilitation skills (Burge \& Howard, 1990). And as per now, the online computer-mediated distance learning has taken place and extended the interaction strategies.

Computer-mediated education has also caught the attention of face-to-face teaching institutions. It presents such institutions with possibilities for engaging with current students who seek greater flexibility in the delivery of courses, and with new cohorts of distance students (Bill \& Mary ,2012). Not only the flexibility to students matters but also the learning environment and the response to the challenges the world is facing have imposed the use of IT tools to allow teaching and learning continue. The current situation of COVID-19 pandemic spread has forced all the institutions to work from home. Students shouldn't be left behind. Even though they were not much conversant with e-learning platforms, they had to be online learning.

Distance education, also called distance learning, provides learning chances to people who could not afford time or money for traditional classes or who lived in remote areas far from schools. Because of the expansion of the Internet in recent years, the Internet has become the most important tool for delivering distance education (Liudmila \& Nataliya, 2020).

The guidance note on Education Systems' response to COVID19 published by UNESCO on 25th March 2020 indicated that over a billion students were affected by closure of schools due to that pandemic. This note stated that while schools are closed, many countries have turned to distance learning as a means of mitigating for lost time in continuing education services (UNESCO, 2020). This was quite necessary and important but some challenges have been discovered. Some institutions post resources on their websites but that is not necessarily online teaching/learning. Infrastructure and familiarity with the tools to many teaching staff and students are the major challenges of teaching and learning process. We shall discuss these challenges in detail in next sections.

Distance learning makes it much easier for some students to complete a degree or get additional job-training while balancing work and family commitments. Because the hours when class work can be completed are flexible, as most distance learning programs allow students to work at their own place and on their own time, many students can complete their work during times when they are free, rather than scheduling their lives around a set classroom time (Liudmila \& Nataliya, 2020). Due to COVID-19 pandemic, students were requested to learn from their homes. This was possible since the distance learning mode was introduced by governments to keep those students in curricular activities mood. Students learn independently without their teachers/trainers regular guidance.

E-learning enhances the efficacy of knowledge and qualifications via ease of access to a huge amount of information. It is able to provide opportunities for relations between learners by the use of discussion forums. Through this, e-learning helps eliminate barriers that have the potential of hindering participation including the fear of talking to other learners. E-learning motivates students to interact with other, as well as exchange and 
respect different point of views. E-learning eases communication and also improves the relationships that sustain learning. E-learning is cost effective in the sense that there is no need for the students or learners to travel. It is also cost effective in the sense that it offers opportunities for learning for maximum number of learners with no need for many buildings.... E-learning helps compensate for scarcities of academic staff, including instructors or teachers as well as facilitators, lab technicians etc (Valentina \& Nelly, 2014).

Even though this learning mode is advantageous, it has some challenges for those who are less motivated like the lack of interaction with other students in the classroom, difficult technology and accessibility, no immediate feedback, some employers do not accept online degrees ...

With respect to clarifications, offer of explanations, as well as interpretations, the e learning method might be less effective that the traditional method of learning. The learning process is much easier with the use of the face to face encounter with the instructors or teachers. When it comes to improvement in communication skills of learners, e-learning as a method might have a negative effect. Though might have an excellent knowledge in academics, they may not possess the needed skills to deliver their acquired knowledge to others. Since tests for assessments in e-learning are possibly done with the use of proxy, it will be difficult, if not impossible to control or regulate bad activities like cheating. E-learning may also probably be misled to piracy and plagiarism, predisposed by inadequate selection skills, as well as the ease of copy and paste. E-learning may also deteriorate institutions' role socialization role and also the role of instructors as the directors of the process of education. Also not all fields or discipline can employ the e-learning technique in education. For instance the purely scientific fields that include practical cannot be properly studies through e-learning. Research studies have argued that e learning is more appropriate in social science and humanities than the fields such as medical science and pharmacy, where there is the need to develop practical skills. E-learning may also lead to congestion or heavy use of some websites. This may bring about unanticipated costs both in time and money disadvantages (Valentina \& Nelly, 2014)

\subsection{Open and Distance Learning in Developing World}

With the introduction of technologies, the world has become a small village that in one way or another one can tour in a short period of time. Its components (countries, nations, states ...) have been economically classified depending on the level of industrialization in each component and its per capita income level. Technology has changed life and the ways in which things are done.

Due to the labor market demands, some employs lost their jobs since technology has changed the way of thinking and working styles and environment. "Adults who may have lost their jobs are coming back into higher education in order to equip themselves with the skills that they need in order to compete for ever-scarcer vacancies. As this happens, higher education institutions, already battered by their losses and constraints, have to balance the demand for access from mature and new learners, for a limited number of places. In addition there is bound to be a shift towards those courses that will provide the knowledge and skills for economic relevance and earning power. Commerce, science and technology are likely to be over-subscribed, once again at the expense of the humanities, whose relevance in a technology-driven world, seems to be diminishing steadily" (University of South Africa, 2009). That is how Online and Distance Learning started not only in developed countries, but also in developing ones. "For the Developing World ODL is a promising and practical strategy to address the challenge of widening access thus increasing participation in higher education. It is increasingly being seen as an educational delivery model which is cost-effective without sacrificing quality" (University of South Africa, 2009).

\subsection{Open and Distance Learning in Africa}

Africa as a continent where most of its countries make a big number of Third World Countries, there are no enough infrastructure, no enough and qualified human resources, it was necessary to introduce Open and Distance Learning to fill in the gap that is between the labor market offer and supply. In Africa where resources are scarce and higher education provision is poor, ODL has been accepted as a viable, cost effective means of expanding provision without costly outlay in infrastructure (University of South Africa, 2009).

The field of Open and Distance Learning (ODL) is moving from a peripheral form of educational approach and delivery to one that is a central pillar in many countries' and institutions' education plans and delivery. The evolution of information and communication technologies has had a positive effect on the development of distance education and open learning (Association for the Development of Education in Africa (ADEA), April 2002).

Many of the countries that have been using distance or correspondence education have continued to employ first generation methodologies (correspondence courses with text-based materials similar to those used in the classroom and delivered through the postal system), while some have introduced second generation methodologies (mainly print-based and characterized by self-instructional design) and third generation methodologies (selfinstructional print integrated with audio and video). Very few SSA countries appear to have moved to fourth generation methodologies that use interactive information and communications technology (ICT) to support course delivery and learning (Association for the Development of Education in Africa (ADEA), April 2002). The COVID- 
19 pandemic has even raised the African, as well as the global countries' interests to promote ODL in order to keep students in academic mood and learning environment. There were no other solutions as it had been instructed by UNESCO on March 25th 2020. While schools are closed, many countries have turned to distance learning as a means of mitigating for lost time in continuing education services. Some countries are simply putting resources on their website, and making available more products, but not necessarily online classes (UNESCO, 2020).

A study conducted in Zimbabwe to find out the ODL students challenges revealed that the most reported challenges were lack of sufficient time to study, difficulties in access and use of ICT, ineffective feedback and lack of materials (Maxwell, Mapuranga, Chiwanza, \& Shupikai, 2015). Another study also found out technological and pedagogical challenges affecting the students learning. In this regard, they reported frequent power and internet failures (Karsenti \& Collin, 2010).

\subsection{Open and Distance Learning in Rwanda}

Studies conducted on ODL in Rwanda have assessed its implementation and some findings have been identified. In an expository study conducted on Distance Learning Program of Teachers at Kigali Institute of Education; the researcher stated that Kigali Institute of Education was established in January 1999 by the Government of Rwanda to help address the shortage of qualified teaching staff at the secondary level and the shortage of managerial staff needed to run technical and vocational training institutions. She continues stating that Although Kigali Institute of Education started by offering an on-campus program, in order to fulfill its mission of providing Rwanda with qualified teachers, the Institute determined it needed to establish a distance learning (DL) program as a compliment to its existing on-campus learning and teaching model. Distance learning became an alternative for two reasons. First, because there are many under qualified in-service teachers working on the ground, and second, there are no qualified teachers to replace them should they leave for training and upgrading. Distance education, therefore, was chosen as a viable mode of training delivery for this targeted group of educators (MUKAMUSONI, September 2006).

In her findings, she found that most of the staff had little experience in delivering through Distance Learning mode before joining the program. This was due to an unusually wide variety of skills that are required for both on the part of academic and non-academic staff, the competencies required to organize and run a DL program that were not typically available. Although capacity building and staff development are important to all aspects of the Institute's DL program, it becomes even more important in course materials development because, in most cases, DL course materials are developed by lecturers from on-campus programs (MUKAMUSONI, September 2006).

Another study was conducted to find out the practices and challenges of Distance Training Program under Kigali Institute of Education and many challenges have been identified. Amongst them, there was: lack of adequate infrastructure, students drop out, lack of working and teaching-learning materials, irregularities in students attendance, lack of assistants who would assist in students support, content which was difficult to understand, and limited interaction between trainers-trainees and trainees-trainees (NDAYAMBAJE, BIMENYIMANA, \& NDAHAYO, 2015)

On the other hand, in a study conducted to analyze the interplay between policy formulation and interpretation in terms of historical practices of ODL in Rwanda has come out with the findings revealing that though policies extolled ODL potential to increase access, relevance and inclusion in education, and though they highlight the need to improve quality in higher education through affordable, scalable and sustainable technologies, implementing institutions tend to adopt contentious approaches to cope with a dual mode (Mukama, 2018).

\section{Research methodology}

\subsection{Research design}

The research used the descriptive survey. The descriptive survey was used to collect and analyse data from a few sample considered to be representative of TVET students in Rwanda Polytechnic. The purpose is just to assess the perception of TVET students in Rwanda Polytechnic on the benefits they had and challenges encountered in learning through E-learning platform established as a response to classrooms closure due to COVID-19 pandemic.

\subsection{Target population}

The research was conducted in Rwanda Polytechnic, and the target population was IPRC Kigali students. The accessible population will be the 2019/2020 Academic Year; 70 Year one students in Mechanical Engineering, Automobile option and 80 Year one students in Civil Engineering, Construction Technology. These numbers make a total of 150 students.

\subsection{Sample size}

The sample size was determined by Slovin's Formula as the population size is definite. That formula is given and explained as follows: 


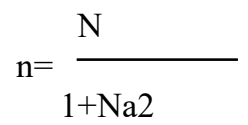

Where:

$\mathrm{a}=$ level of significance or reliability level (equals to 0.05 )

$\mathrm{N}$ : Population size

n: sample size.

The students sample size will be: 150 $=109$ students

Thus, the sample size drawn from the target population of 150 was 109 student respondents. The questionnaire was sent randomly, via Google forms, to the above respondents but 52 of them were able to respond and submit back it to the researcher.

\subsection{Sampling techniques}

In IPRC Kigali, There are 5 departments. We used the non-probability sampling technique whereby we used the purposive sampling. Purposive sampling refers to the selection of sample on the basis of informed judgment that the group is likely to be representative. Two departments were selected as a sample of IPRC Kigali Departments. The purposive sampling technique used the following inclusion criteria to qualify them in this: for the studentrespondents (1) Studying in year one; (2) from the selected options under the study. The student-respondents were chosen in simple random sampling from the students. The researchers sent the questionnaire to different students pursuant to the students' progress in Rwanda Polytechnic E-learning platform.

\subsection{Data collection Instruments}

The study was conducted using questionnaires. The questionnaires contained close-ended questions to allow the respondents not to deviate from the research objectives, to determine their attitude about the benefits and challenges they are getting/encountering during this E-learning period. Attitude scale method was used. This is a method called Likert Method of summated ratings. It consists of collecting a number of statements about a subject, and assigning a five-scale value to each of the responses.

\section{Findings}

The findings of this study are presented pursuant to the research objective which was to assess the perception of IPRC Kigali students on the current e-learning opportunities and the available challenges. The researchers used twenty-one (21) questions to test the concerned respondents. The summary of respondents' views is presented in the following tables. The questionnaire has been answered by 52 student-respondents who returned the questionnaires.

4.1 IPRC Kigali students' E-Learning current progress information by August 2020

The study sought to identify the IPRC Kigali students' current progress in Rwanda Polytechnic E-Learning platform and the following results were revealed: 
Table 1: IPRC Kigali students’ E-Learning current progress information by August 2020

\begin{tabular}{|c|c|c|c|}
\hline Progress & Frequency & Percent & $\begin{array}{l}\text { Cumulative } \\
\text { Percent }\end{array}$ \\
\hline $\begin{array}{l}\text { I frequently visit my e-learning platform and do the assigned } \\
\text { activities }\end{array}$ & 15 & 28.8 & 28.8 \\
\hline $\begin{array}{l}\text { I frequently visit my e-learning platform and do some of the assigned } \\
\text { activities }\end{array}$ & 11 & 21.2 & 50.0 \\
\hline I sometimes visit the platform and do assigned activities & 3 & 5.8 & 55.8 \\
\hline I sometimes visit the platform and do some of the assigned activities & 11 & 21.2 & 76.9 \\
\hline I sometimes visit the platform but do not do assigned activities & 1 & 1.9 & 78.8 \\
\hline $\begin{array}{l}\text { I only attend classes on communicated schedules and do assigned } \\
\text { activities }\end{array}$ & 2 & 3.8 & 82.7 \\
\hline $\begin{array}{l}\text { I have joined my class on the platform but never did and class } \\
\text { activities }\end{array}$ & 5 & 9.6 & 92.3 \\
\hline I have never joined the platform & 3 & 5.8 & 98.1 \\
\hline Other & 1 & 1.9 & 100.0 \\
\hline Total & 52 & 100.0 & \\
\hline
\end{tabular}

As shown in table No1, the results from the respondents, $50 \%$ of the students frequently visit RP e-learning platform, whereas $28.9 \%$ of them sometimes visit it and $3.8 \%$ attend online classes on communicated schedules and do assigned activities. On the other hand, 9.6\% have joined classes and never did any class activities while $5.8 \%$ of them have never joined the platform.

4.2 RP/IPRC Kigali E-Learning opportunities during COVID-19 spread

To determine the opportunities IPRC Kigali students have got during the confinement, the researchers asked them the questions related to the benefits they are gaining from the E-Learning platform that was introduced by Rwanda polytechnic to help them continue their academic progress. The following are the findings:

Table 2: IPRC Kigali E-Learning system opportunities during COVID-19 spread

\begin{tabular}{|c|c|c|c|c|c|}
\hline E-Learning opportunities & $\begin{array}{l}\text { SA } \\
(\% 0)\end{array}$ & $A(\%)$ & $\mathbf{N}(\%)$ & $\begin{array}{l}\text { D } \\
\text { A(\%) }\end{array}$ & $\operatorname{SDA}(\%)$ \\
\hline $\begin{array}{l}\text { It will be easier for me to read and complete my modules } \\
\text { before the resume of face to face learning. }\end{array}$ & $7(13.5)$ & $\begin{array}{c}14 \\
(26.8)\end{array}$ & $12(23.1)$ & $\begin{array}{c}11 \\
(21.2)\end{array}$ & $8(15.4)$ \\
\hline $\begin{array}{l}\text { I am successfully learning independently without my } \\
\text { teachers/trainers regular guidance. }\end{array}$ & $9(17.3)$ & $\begin{array}{c}18 \\
(34.6)\end{array}$ & $11(21.2)$ & $\begin{array}{c}8 \\
(15.4)\end{array}$ & $6(11.5)$ \\
\hline $\begin{array}{l}\text { Through E-learning, it is very easy for me to access to a } \\
\text { huge amount of information. }\end{array}$ & $3(5.8)$ & $\begin{array}{c}12 \\
(23.1)\end{array}$ & $14(26.9)$ & $\begin{array}{c}14 \\
(26.9)\end{array}$ & $9(17.3)$ \\
\hline $\begin{array}{l}\text { Our E-learning platform is able to provide opportunities } \\
\text { for relations between learners by the use of the discussion } \\
\text { forum }\end{array}$ & $5(9.6)$ & $\begin{array}{c}28 \\
(53.8)\end{array}$ & $11(21.2)$ & $4(7.7)$ & $4(7.7)$ \\
\hline $\begin{array}{l}\text { E-learning is cost effective in the sense that there is no } \\
\text { need for me to travel to and from school. }\end{array}$ & $2(3.8)$ & $\begin{array}{c}21 \\
(40.4)\end{array}$ & $8(15.4)$ & $\begin{array}{c}10 \\
(19.2)\end{array}$ & $11(21.2)$ \\
\hline $\begin{array}{l}\text { E-learning offers opportunities for learning for a } \\
\text { maximum number of trainees with no need for many } \\
\text { buildings. }\end{array}$ & $12(23.1)$ & $\begin{array}{c}23 \\
(44.2)\end{array}$ & $8(15.4)$ & $\begin{array}{c}6 \\
(11.5)\end{array}$ & $3(5.8)$ \\
\hline $\begin{array}{l}\text { E-learning helps compensate for scarcities of academic } \\
\text { staff, including instructors as well as lab technicians since } \\
\text { one staff can serve as many students as possible }\end{array}$ & $11(21.2)$ & $\begin{array}{c}22 \\
(42.3)\end{array}$ & $9(17.3)$ & $\begin{array}{c}6 \\
(11.5)\end{array}$ & $4(7.7)$ \\
\hline Mean (\%) & 13.47 & 37.89 & 20.07 & 16.2 & 12.37 \\
\hline
\end{tabular}

The findings in Table 2 revealed more than $50 \%$ of the student-respondents find opportunities in the ELearning system that was introduced by Rwanda Polytechnic to facilitate them in continuous learning process. On the other hand, almost $29 \%$ of them were not convinced with the research statements related to the benefits they gain from the platform.

4.3 RP/IPRC Kigali E-Learning challenges during COVID-19 spread

To identify the challenges IPRC Kigali students have encountered during confinement, the researchers asked them the questions related to the difficulties met at the E-Learning platform introduced by Rwanda polytechnic to help them continue their academic progress. The following are the findings: 
Table 3: IPRC Kigali E-Learning platform challenges during COVID-19 pandemic spread

\begin{tabular}{|c|c|c|c|c|c|}
\hline E-Learning challenges & $\begin{array}{l}\mathrm{SA} \\
(\% 0)\end{array}$ & $A(\%)$ & $\mathrm{N}(\%)$ & D A(\%) & $\operatorname{SDA}(\%)$ \\
\hline $\begin{array}{l}\text { Lack of learning resources like a computer or a smart } \\
\text { phone prevented me from joining the class (those } \\
\text { who have not yet joined) }\end{array}$ & $10(19.2)$ & $5(9.6)$ & $29(55.8)$ & $3(5.8)$ & $5(9.6)$ \\
\hline $\begin{array}{l}\text { Difficult access to learning resources like a } \\
\text { computer or a smart phone prevented me from } \\
\text { regularly accessing the platform }\end{array}$ & $16(30.8)$ & $\begin{array}{c}13 \\
(25.0)\end{array}$ & $10(19.2)$ & $7(13.5)$ & $6(11.5)$ \\
\hline $\begin{array}{l}\text { Some of the students mindsets prevent them from } \\
\text { accessing the E-learning platform }\end{array}$ & $4(7.7)$ & $\begin{array}{c}16 \\
(30.8)\end{array}$ & $7(13.5)$ & $8(15.4)$ & $17(32.7)$ \\
\hline $\begin{array}{l}\text { E-Learning limits interaction between trainers- } \\
\text { trainees and trainees-trainees }\end{array}$ & $10(19.2)$ & $\begin{array}{c}22 \\
(42.3)\end{array}$ & $6(11.5)$ & $10(19.2)$ & $4(7.7)$ \\
\hline $\begin{array}{l}\text { It is difficult to access E-learning and use its } \\
\text { technology }\end{array}$ & $7(13.5)$ & $\begin{array}{c}14 \\
(26.9)\end{array}$ & $6(11.5)$ & $18(34.6)$ & $7(13.5)$ \\
\hline $\begin{array}{l}\text { I don't receive immediate feedback from my } \\
\text { lecturers }\end{array}$ & $9(17.3)$ & $\begin{array}{c}17 \\
(32.7)\end{array}$ & $8(15.4)$ & $8(15.4)$ & $10(19.2)$ \\
\hline $\begin{array}{l}\text { It is impossible to control malpractices like cheating } \\
\text { in E-learning }\end{array}$ & $13(25.0)$ & $\begin{array}{c}24 \\
(46.2)\end{array}$ & $4(7.7)$ & $9(17.3)$ & $2(3.8)$ \\
\hline $\begin{array}{l}\text { E-learning may be misled to piracy and plagiarism, } \\
\text { predisposed by inadequate selection skills, as well as } \\
\text { the ease of copy and paste }\end{array}$ & $12(23.1)$ & $\begin{array}{c}17 \\
(32.7)\end{array}$ & $6(11.5)$ & $10(19.2)$ & $7(13.5)$ \\
\hline $\begin{array}{l}\text { E-learning may also deteriorate institutions' role } \\
\text { socialization role and also the role of instructors as } \\
\text { the directors of the process of learning }\end{array}$ & $13(25.0)$ & $\begin{array}{c}13 \\
(25.0)\end{array}$ & $10(19.2)$ & $11(21.2)$ & $5(9.6)$ \\
\hline $\begin{array}{l}\text { Our field of education cannot match with e-learning } \\
\text { mode since we need more practice than tutorials }\end{array}$ & $23(44.2)$ & $\begin{array}{c}10 \\
(19.2)\end{array}$ & $2(3.8)$ & $12(23.1)$ & $5(9.6)$ \\
\hline I frequently encounter power and internet failures & $5(9.6)$ & $\begin{array}{c}13 \\
(25.0)\end{array}$ & $9(17.3)$ & $10(19.2)$ & $15(28.8)$ \\
\hline $\begin{array}{l}\text { Our lecturers/instructors have a little experience in } \\
\text { delivering through Distance Learning mode }\end{array}$ & $1(1.9)$ & $5(9.6)$ & $12(23.1)$ & $13(25.0)$ & $21(40.4)$ \\
\hline $\begin{array}{l}\text { When I am challenged by the platform content, I } \\
\text { lack an assistant to support me }\end{array}$ & $6(11.5)$ & $\begin{array}{c}17 \\
(32.7)\end{array}$ & $8(15.4)$ & $11(21.2)$ & $10(19.2)$ \\
\hline $\begin{array}{l}\text { Most of my modules' contents are difficult to } \\
\text { understand without the lecturers' face to face }\end{array}$ & $19(36.5)$ & $8(15.4)$ & $5(9.6)$ & $10(19.2)$ & $10(19.2)$ \\
\hline
\end{tabular}

interaction and guidance

$\begin{array}{llllll}\text { Mean }(\%) & 20.32 & 26.65 & 16.75 & 19.24 & 17.02\end{array}$

The findings in Table 3 revealed almost $47 \%$ of the student-respondents encountered challenges in using Rwanda Polytechnic E-Learning system. On the other hand, almost $37 \%$ of them were found those challenges as opportunities for them to continue their learning activities as face to face teaching/learning had been closed due to COVID-19 pandemic spread.

\section{Discussion of the results}

This section deals with the major findings of the study and its significance to the area of knowledge in the light of previous studies that either support our findings or differ from them. To discuss results in a logical and clear way, the research objective was referred to.

Is it has been stated in the findings, there have been discovered the opportunities in the established E-Learning platform to cover the hindrances that had been created by schools closure to contain COVID-19 pandemic. More than $60 \%$ of the student-respondents supported the statement saying that their E-learning platform is able to provide opportunities for relations between learners by the use of the discussion forum. Only $15.4 \%$ did not agree with the statement. This is to show that COVID-19 pandemic did not cut off their relations since the Management of Rwanda Polytechnic thought about how students should keep in touch. The majority did not disappear. They continued working together through the learning platform.

In addition, the respondents agreed that E-learning offers opportunities for learning for a maximum number of trainees with no need for many building. Therefore more than $67 \%$ of them found this as an opportunity. On top of this, students may learn wherever they are. There is no need to be in a particular building. Just having internet and a Smartphone or a computer will allow him to follow his/her courses. More than $63 \%$ also agreed that a small number of teaching staff may deliver courses to a big number of students at the same time. The challenge they may face to grading the students' works since it may be time consuming. 
On the other hand, challenges have been identified in this study. It has been discovered that IPRC Kigali students faced challenges of lacking learning resources like a computer or a smart phones that prevented some of them from joining the classes (29.8\%), access to learning resources like a computer or a smart phone was difficult to some of them (55\%) and this prevented them from regularly accessing the platform. An average number $(50 \%)$ of the respondents confirmed that E-learning may deteriorate institutions' role socialization and also the role of instructors as the directors of the process of learning. Institutions play a very important role in socialization. Therefore, this may be a challenge to address as far as E-Learning is concerned.

The respondents did not agree with some statements that were identified by different research studies to be the challenging issues. The majority of them did not accept that the students' mindsets prevent them from accessing the E-learning platform (48.1\%). They didn't also agree on the statement that lecturers/instructors have a little experience in delivering through Distance Learning mode (65.4\%). This shows that they are proud of their teaching staff. This may lead to concluding that the challenges they faced during this period are not from their teaching staff.

The major challenging issues that were discovered are that: (1) the respondents field of education cannot match with e-learning mode since they need more practice than tutorials $(63.4 \%) ;(2)$ they also found it impossible to control malpractices like cheating in E-learning (71.2\%). These challenges are due to the nature of TVET modules. Tutorials are being used but there is no way to follow up individual student as the principle of competence based training. During examination, it is necessary to bring the students where instructors are to control malpractices. Therefore, they found this mode to be challenging on both sides; trainers and trainees.

\section{Conclusion and recommendations}

This paper examined the opportunities available for IPRC Kigali students who were learning via Rwanda Polytechnic E-Learning platform, established to maintain the learning process and contain COVID-19 pandemic spread. It also examined the challenges they encountered during this period. The findings revealed that more than $40 \%$ of the student-respondents confirmed that it would be easier for them to read and complete their modules before the campus reopens. They also (52\%) revealed that they were successfully learning independently without their teachers/trainers regular guidance. It was agreed that Rwanda Polytechnic E-learning platform is able to provide opportunities for relations between learners by the use of the discussion forum. The majority found Elearning to be cost effective too. They confirmed that there is no need for them to travel to and from school. Elearning offers opportunities for learning for a maximum number of trainees with no need for many buildings.

On the other hand, the respondents found some challenges hindering them from successfully learning. Firstly, it was found difficult to access learning resources like computers or smart phones, which prevented them from regularly accessing the platform. Secondly, some of the students' mindsets prevented them from accessing the Elearning platform. it is impossible to control malpractices like cheating in E-learning, Lastly, when students were challenged by the platform content, they lacked effective support while most of their modules' contents were difficult to understand without the lecturers' face to face interaction and guidance.

Pertaining to the above findings, the following recommendations would make the integration of E-learning more effective than the traditional learning model that RP used to have before COVID 19 pandemic . To address the issue of impossibility to control malpractice; the use of appropriate software used in universities like Global Health University (GHU), Carnegie Mellon University (CMU) and African Leadership University (ALU) would be adopted. The government should speed up the distribution of laptops to students who have not received them yet. Students who resist to change should be sensitized to change their mindsets and join E-Learning platform. Lecturers should design effective E-learning resources including many practical exercises. They should also provide timely feedback otherwise students would consider the platform inefficient. Both trainees and trainers should be trained on the use of ICT in general and E-Learning and be equipped with independent study skills to enhance the students self-study. The use of emerging technologies like zoom, Microsoft teams, WebEx, Google meet ... videoconferencing, social media, and other virtual classrooms would be considered.

\section{References}

Association for the Development of Education in Africa (ADEA). (April 2002). Distance Education and Open Learning In Sub-Saharan Africa: A Literature Survey On Policy And Practice . Abidjan: The Commonwealth of Learning .

Bill , A., \& Mary , S. (2012). History and heritage in distance education. Journal of Open, Flexible, and Distance Learning , 1-10.

Burge, E. J., \& Howard, J. L. (1990). Audio conferencing in graduate education: A case study. Amercian Journal of Distance Education , 3-13.

Harerimana, A., Ntombifikile., M. G., Hewing, H., Maniriho, F., Kyamusoke, E. B., Mukankaka, A., et al. (2016). E-Learning in Nursing Education in Rwanda: Benefits and Challenges. An Exploration of Participants' Perceptives. IOSR Journal of Nursing and Health Science (IOSR-JNHS) , 64-92. 
Ivy, R. M., \& Jane, I. E. (2016). OPEN AND DISTANCE LEARNING: BENEFITS AND CHALLENGES OF TECHNOLOGY USAGE FOR ONLINE TEACHING AND LEARNING IN AFRICA. Maseru: Botho University.

Karsenti, T., \& Collin, S. (2010). Open and distance learning: What are the benefits for Africa, and what is its future? World Conference on E-Learning in Corporate, Government, Healthcare, and Higher Education (pp. 1869-1892). Montreal: ResearchGate.

Liudmila, V., \& Nataliya, B. (2020). http://dspace.nuft.edu.ua/jspui/bitstream. Kiev: National University of Food Technologies, Ukraine.

Maxwell, M. C., Mapuranga, B., Chiwanza, K., \& Shupikai, Z. (2015). Challenges for Open and Distance learning (ODL) Students: Experiences from Students of the Zimbabwe Open University. Journal of Education and Practice, 59-66.

Mukama, E. (2018). From Policies to Implementation of Open Distance Learning in Rwanda: A Genealogical and Governmentality Analysis. Journal of Learning for Development - JL4D , 40-56.

MUKAMUSONI, D. (September 2006). Distance Learning Program of Teachers' at Kigali Institute of Education: An expository study. International Review of Research in Open and Distance Learning , 1-10.

NDAYAMBAJE, I., BIMENYIMANA, T., \& NDAHAYO, V. (2015). A study on the practices and challenges of Distance Training Programme (DTP) under Kigali Institute of Education (KIE). Rwandan Journal of Education , 69-76.

https://en.unesco.org/themes/education-emergencies/coronavirus-school-closures. Retrieved June 28, 2020, from UNESCO Web site: https://en.unesco.org

UNESCO. (2020). Guidance Note on Education Systems' Response to COVID19. Paris: UNESCO.

University of South Africa. (2009). OPEN DISTANCE LEARNING IN THE DEVELOPING WORLD:trends, progress and challenges. Maastricht: University of South Africa.

Valentina, A., \& Nelly, A. (2014). The role of e-learning, the advantages and disadvantages of its adoption in Higher Education. International Journal of Education and Research, 397-410. 